not only the tube which passes into the distillation flask, but also the tube within the bulb has an opening on the side and a jet at the end.

The form of this distillation tube and its advantage

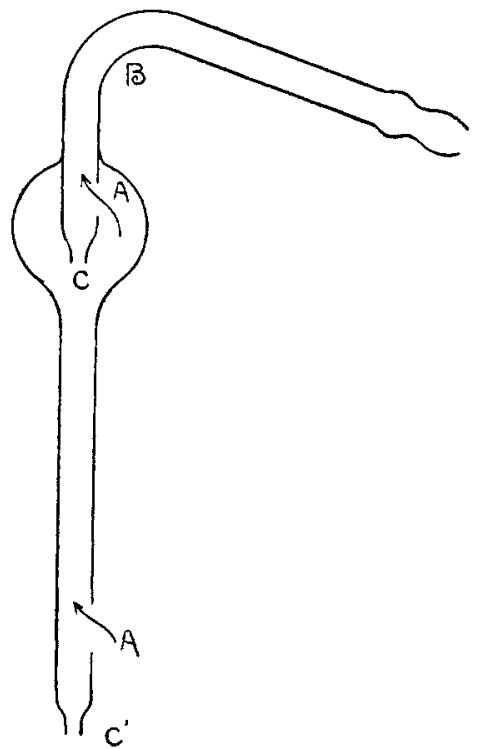

tube in ordinary use will be plainly seen in the accompanying illustration.

The vapor passes in through the side openings $A$ and $A^{\prime}$, and whatever condenses in the tube below the point $B$ passes back into the distillation flask through the jets $C$ and $C^{\prime}$.

The possibility of liquid from the distillation flask being thrown into the tube is avoided, and the current of vapor does not interfere with the return of condensed liquid. The jets $C$ and $C^{\prime}$ are two $\mathrm{mm}$. inside diameter and they always remain filled with returning liquid when in use. The tubing used in making these distillation tubes is from seven $\mathrm{mm}$. to eight $\mathrm{mm}$. inside diameter. The side openings $A$ and $A^{\prime}$ should be nearly as large, and the bulb about five $\mathrm{cm}$. in diameter. The length of the tube below the bulb is twelve $\mathrm{cm}$. and that above the bulb about the same.

UNIVERSTTY OF ILIINOIS, EXPERIMENT STATION.

\title{
REMARKS ON MR. AUCHY'S PAPER ON THE VOLUMETRIC DETERMINATION OF MANGANESE. ${ }^{\prime}$
}

\author{
BX GeORge C. STONE.
}

Receiverl January $I x$, I8966.

I $N$ the December number of the Journal of the American Chemical Society there is a paper by Mr. George Auchy on the "Volumetric Determination of Manganese," in which he advocates the use of Volhard's method, in which I heartily agree

1 Read before the New York Section. 
with him, but the method as he describes it, seems to me unneccesarily complicated.

Mr. Auchy criticises Williams' method and refers to the discussion of it which occurred some years since. ${ }^{1}$ At that time I satisfied myself that the method as originally described by Williams was not accurate, but in a modified form I used it for several years with good results until $I$, too, was treated to the same disagreeable surprise as Mr. Auchy, a number of manganese determinations came very low. On examination I found that this was due to the decomposition of the oxalic acid solution. I then gave up the method and have since used Volhard's with uniformly satisfactory results, except where there are only a few hundredths of a per cent. of manganese present, in which case I found the method of oxidizing by peroxide of lead, reducing by standard arsenious acid and titrating back by permanganate to work well.

Volhard's method, as I have used it, is as follows: The quantity of material taken for analysis should contain between 0.05 and o.I5 grams of manganese. If it is an alloy, dissolve in nitric acid of about r.ro sp. gr.; if an ore or cinder, dissolve in hydrochloric acid and boil with a little potassium chlorate. In either case use but a small excess of acid. Cool, wash into a half liter flask with cold water and add an emulsion of zinc oxide until the precipitate curdles; the change in the appearance of the precipitate is sharp and distinct. Dilute to the mark, mix thoroughly, pour into a beaker and allow the precipitate to settle. Decant off exactly Ioo cc. into a four inch casserole, dilute to about $200 \mathrm{cc}$, heat nearly to boiling and titrate rapidly with permanganate, one cc. of which should equal 0.00 I gram of manganese (about I.99 grams potassium permanganate in one liter). The greater part of the permanganate should be added at once and the solution very vigorously stirred. For this purpose a glass rod bent to a hook is very convenient, the hook, of course, being in the solution.

I have made a number of experiments to see if it makes any difference whether nitric, hydrochloric or sulphuric acid is used, and have not found that it does, provided the iron is oxidized. For

I Trans. Am. Inst. Min. Eng., I1, 514; 12, 295-449; Chem. New/, 188 ; , $176-273$. 
neutralizing I use commercial zinc oxide, which contains a trifling amount of manganese, but under the conditions in which it is used this apparently does not go into solution. To test this point, I made a number of duplicate analyses, neutralizing one of each pair with zinc oxide and the other with barium carbonate; in all cases the results agreed well. It is not necessary to filter the solution, the iron precipitate settles very rapidly and completely, and if a little of the precipitate goes with the solution, it makes no difference. I think the trouble Mr. Auchy mentions in getting good results with steels low in manganese when a large excess of zinc oxide is used, is due to not having sufficient manganese present, as it is difficult to make a very small precipitate clot together so as to give a clear solution in which the color of the end reaction shows distinctly. I have often tried adding a very large excess of zinc oxide, but have never found it to interfere, provided the manganese was within the linits given above.

The method is very rapid, a determination of manganese in spiegel can easily be made in haif an hour; ores usually take a little longer, as they are more difficult to dissolve.

\section{PROBABLE PRODUCTION OF PERMANGANATE BY DIRECT COMBUSTION OF METALLIC MANGANESE.}

BY GEORGE C. STONE.

Receiver January $\mathrm{t}, \mathrm{j} 896$.

\HEN casting at a Spiegel furnace, a good deal of iron and manganese is always burned at the tap hole, giving a very hot flame and clouds of reddish fume, the hotter the furnace and the higher the percentage of manganese in the iron, the more sparks and fume. To protect themselves from these sparks the men often put a sheet iron screen over the run and tap holes. One day some water was accidentally spilled on this screen immediately after casting. It at once took the deep purple color of a permanganate solution; unfortunately the screen was upset and the solution spilled before I could secure any of it for further examination. At the time the furnace was working very hot, making a high grade spiegel and a basic cinder.

\section{DISCUSSION.}

Dr. Rosell called attention to the fact that potassium permanganate when heated to a red heat would decompose, and that the

1 Read before the New York Section. 